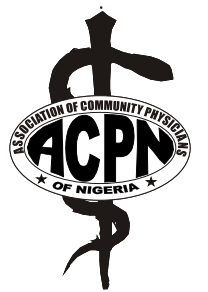

\title{
Childhood malaria: mothers' perception and treatment- seeking behaviour in a community in Ebonyi State, South East Nigeria
}

\section{AP Agu and JO Nwojiji}

\author{
Department of Community Medicine, Faculty of Clinical Medicine, Ebonyi State University, \\ Abakaliki, Nigeria
}

\section{KEY WORDS:}

Childhood malaria

Mothers' perception

Treatment-seeking

behaviour

Early diagnosis

Effective treatment

Community based

\section{Abstract}

Context: Childhood malaria continues to be a major cause of childhood morbidity and mortality. Caregivers ability to detect the illness in children early and institute effective treatment is critical to illness outcome. The investigation of mothers' perception of malaria and treatment-seeking behaviour in childhood malaria in a community in Ebonyi State, South-East Nigeria was therefore the aim of this study.

Methods: Using a cross-sectional descriptive study design, interviewer-administered structured questionnaires were administered to a sample of 236 mothers drawn by multi-staged sampling to collect information on their perception of and recognition of signs and symptoms of malaria in children and treatment-seeking behaviour.

Findings: The mean age of the respondents was 40.63 years. Only $35.2 \%$ of them knew the cause of malaria. No significant association was found between education and this knowledge. Majority (59.3\%) of the respondents perceived malaria as a serious problem. Fever and chills were the most common symptoms recognised by $72 \%$ and $60.2 \%$ of the mothers respectively as being associated with malaria in children. The incidence of history of fever, indicative of malaria in children of the respondents within one month of the survey was $74.6 \%$. The health centre was the most preferred choice where treatment was first sought $(21 \%)$ for the bout of fever while government hospitals and community health workers were sources of treatment for $15.9 \%$ and $14.6 \%$ respectively. Other sources of treatment were treatment at home, patent medicine dealers, private hospital and traditional healers used by $13.6 \%, 10.2 \%$ and $7.4 \%$ respectively.

The dominant reasons for choice of the health centre were availability of Doctor / trained personnel $(73 \%)$ and good service $(67.6 \%)$. Proximity was the major factor $(92.3 \%)$ for choice of the community health workers. Low cost of care and good personal experience were the main reasons for the choice of traditional healers and home treatment respectively. The mean number of days between when illness was noticed and time treatment was instituted was 3 days.

Conclusion: The low level of awareness of mothers of the cause of malaria, the poor treatmentseeking behaviour shown by the low level of use of the health facilities as a place where treatment is first sought, and the delay in seeking treatment for childhood malaria, suggest a need for intensified health education intervention programmes. Measures to relieve poverty and reduce cost of allopathic care should also be put in place.

\section{Introduction}

Malaria is the most prevalent parasitic endemic disease in Africa with more than $80 \%$ of the population south of the Sahara at risk of the disease ${ }^{1}$. Ninety percent of the estimated 1-2 million deaths globally from malaria annually are estimated to occur in Africa ${ }^{1}$. It is estimated to cause about 700,000 deaths in children every year in the tropics with the highest mortality in the age group 1-4 years ${ }^{2}$. In Nigeria it is one of the leading causes of mortality and morbidity in children aged less than 5 years ${ }^{3}$. It is estimated that over 300,000 people, mainly pregnant women and children die of the disease each year. ${ }^{4}$
Childhood mortality due to malaria has been attributed to poor health service delivery and ignorance associated with cultural beliefs. It has been suggested that social and cultural determinants of behaviour may account for the gap between awareness of modern health measures and health-seeking behaviour. ${ }^{5}$

Prompt access to early diagnosis and effective antimalarial treatment at health facilities is one of the major strategies for reducing the burden of malaria, therefore effective information strategies which address 
understandings and beliefs about the disease are necessary. Early treatment of childhood malaria in children depends upon mothers' perception about malaria and prompt recognition of signs and symptoms of malaria in the child in addition to accessibility and utilization of the appropriate health services. ${ }^{6}$

The aim of this study was to establish mother's perception of aetiology and seriousness of malaria in children, recognition of its sign and symptoms and their treatmentseeking behaviour for childhood malaria. This will inform the development of locally appropriate health education interventions for the control of childhood malaria.

\section{Methodology}

\section{Study location}

This study was carried out in Igbeagu community, Izzi LGA of Ebonyi State, Nigeria. It is about the largest autonomous community in the local government area. The inhabitants are mostly small scale agricultural farmers and petty traders with few civil servants. In the selected villages there are five traditional birth attendants, five traditional healers, numerous patent medicine dealers, two private hospitals and one primary healthcare centre run by the Teaching Hospital.

\section{Methods}

A cross sectional descriptive study was used for the survey. The study population consisted of women below the age of sixty years. It was not specifically targeted at only mothers who had children less than five years of age as it was expected that most of the households would have children under five years.

Multistage sampling method was used. Five villages out of the fifty-two that make up Igbeagu community were selected using the balloting method of simple random sampling. Information on the households was obtained from the village heads. A sample of 250 households was drawn from the five villages studied. The calculation of the sample size was done using the formula for computation of sample size when studying proportions with populations less than ten thousand. ${ }^{7}$ Using simple random sampling, fifty households were selected from each of the five villages to give a total of 250 households. The households were sampled and in each household, one mother was interviewed. Where there was more than one mother, the mother with youngest children was interviewed.

Pre-tested, structured, close-ended questionnaires were administered by field workers after informed consent was obtained. Four field workers recruited were fluent in the local dialect and trained in the survey methods. Information obtained from the respondents included socio demographic data, knowledge of the main cause of the malaria, perception of malaria as a problem, recognition of signs and symptoms of malaria in their children. The history of suspected malaria episodes that occurred in the youngest of the children who had it in the one month preceding the survey was obtained from the mothers. Symptoms of their local name for malaria were elicited.
Respondents were also questioned on their treatmentseeking behaviour for that episode of suspected malaria with regards to where treatment was first sought and reasons for choice of a particular care provider.

The data was computer-analysed using EPI INFO version 6. Data was presented in simple frequencies and percentages. Associations between categorical variables were tested using the Chi-square test at the $P<0.05$ level of significance.

\section{Results}

Out of the 250 mothers sampled, 236 agreed to be interviewed giving a response rate of $94.4 \%$. The mean age of the respondents was 40.63 years \pm 13.12 years. Majority of the respondents (87.3\%) were married and had no formal education $(73.7 \%)$. Farming was the predominant occupation practiced by $75.4 \%$ of the respondents (Table 1 ).

\section{Knowledge of main cause of malaria}

Respondents who did not know the main cause of malaria were in the majority $(64.8 \%)$. Only $35.2 \%$ correctly identified mosquito bite as the main cause of malaria. A few felt that lack of sanitation (6.8\%), sunlight $(5.1 \%)$ and impure water $(4.2 \%)$ were the main causes of malaria.

There was no statistically significant association between education and knowledge of the cause of malaria (Table 2).

\section{Main source of information about malaria}

Relatives/community members were the main sources of information on malaria for $51.7 \%$ of the respondents. Other sources of information included health facilities $(27.1 \%)$, health education campaigns $(16.1 \%)$ and radio (5.1\%).

\section{Recognition of symptoms of malaria in children}

As shown in Table 3, the most common symptoms recognized locally as being associated with malaria in children, was fever (72\%) followed by shivering /chills $(60.2 \%)$. Of the 236 respondents, only $3.8 \%$ associated convulsion with malaria in childhood.

\section{Malaria episodes in children}

The proportion of respondents who had children that had suffered from suspected malaria episodes in the one month preceding the survey was $74.58 \%$. The age range of the children who had had malaria 1-6 years, the mean age was 3 years and percentage under 5 years was $97.6 \%$

\section{Perception of malaria in childhood as a problem}

To assess their perception of malaria as a problem, respondents were asked how serious they thought malaria in childhood was. $59.3 \%$ felt that it was very serious, $39.4 \%$ felt that it was somewhat serious, $10.4 \%$ felt it was not serious at all and $0.9 \%$ indicated they did not know. 


\begin{tabular}{|c|c|c|}
\hline Characteristics & No. & $\%$ \\
\hline \multicolumn{3}{|l|}{ Age } \\
\hline 20 & 4 & 1.7 \\
\hline $21-31$ & 66 & 28.0 \\
\hline $32-42$ & 81 & 34.3 \\
\hline $43-53$ & 33 & 14.0 \\
\hline $54^{+}$ & 52 & 22.0 \\
\hline \multicolumn{3}{|l|}{ Marital Status } \\
\hline Married (monogamous union ) & 123 & 52.1 \\
\hline Married (polygamous union ) & 83 & 35.2 \\
\hline Single & 10 & 4.2 \\
\hline Separated & 3 & 1.3 \\
\hline Divorced & 5 & 2.1 \\
\hline Widowed & 12 & 5.1 \\
\hline \multicolumn{3}{|l|}{ Occupation } \\
\hline arming & 195 & 82.6 \\
\hline Trading & 12 & 5.1 \\
\hline Teaching & 5 & 2.1 \\
\hline Students & 7 & 3.0 \\
\hline Business & 16 & 6.8 \\
\hline Artisan & 1 & 0.4 \\
\hline \multicolumn{3}{|l|}{ Education } \\
\hline No formal education & 174 & 73.7 \\
\hline Primary & 47 & 19.9 \\
\hline Secondary & 11 & 4.7 \\
\hline University / TTC & 4 & 1.7 \\
\hline
\end{tabular}

\section{Treatment-seeking behaviour}

The mean number of days between when the onset of the illness was noticed and time treatment was sought was 3 days. The choices made concerning where treatment was first sought for those children that had malaria in the one month preceding the survey are shown in Table 4. The health centre was the most preferred place of treatment used by $21 \%$ of the respondents while $15.9 \%$ and $14.8 \%$ indicated that they utilized government hospital (Teaching hospital) and the community health workers respectively. Treatment at home was chosen by $13.6 \%$ while 13.6 also chose the patent medicine dealers. The private hospital was utilized by $10.2 \%$ and the traditional healers were consulted by only $7.4 \%$. Neighbours, private laboratories and others constituted $1.7,1.2,0.6 \%$ of care respectively.

The reasons for selection and use of the treatment sources used as a first resort are shown in Table 5. For the health centre, the commonest reason was availability of doctor/trained personnel (73\%) followed by good service $(67.6 \%)$. Good service was also the dominant reason why the government hospital was chosen, while community health workers were mainly patronised because of their proximity $(92.3 \%)$. Majority of those who chose to treat at home first did so because of good personal experience $(75 \%)$ while the private hospital and patent medicine dealers were mostly consulted because of good service 78.6 and $54.2 \%$ respectively. The dominant reason for choosing the traditional healers was that they were inexpensive $(61.5 \%)$.

When asked for the main reason why the health facilities/ community health workers were not consulted as the initial care provider for those who did not do so, lack of money was the reason given by majority $(63.6 \%)$. Other reasons included distance $(11.9 \%)$, could not get transport $(10 \%)$ not severe enough $(8.9 \%)$, did not trust treatment $(3.0 \%)$, family not let me $(1.5 \%)$, religious reasons $(1.5 \%)$.

\section{Discussion}

The low level of awareness of the cause of malaria may be attributed to the fact that the majority of the respondents, who were also uneducated, had their source of information as relatives/community members who were probably as ignorant of the cause of malaria as they were. This contrasts with some studies in parts of Cameroun, Uganda $^{9}$, Kenya ${ }^{10}$, which suggest a considerable level of awareness.

Education did not appear to have a significant bearing on knowledge in this study. This may be due to the high level of respondents without formal education.

It has been observed that the action taken by parents when a child is perceived to have malaria depends on whether they perceive malaria as a major childhood health problem. ${ }^{11}$ In this study, the high perception of malaria as a very serious problem did not translate into a high level of utilization of the health centre as the initial care provider although it was the most preferred of the choices. The percentage of mothers that took their children first to a health facility totalling $47.1 \%$ was higher than that of a similar study in South-East Nigeira. ${ }^{12}$

Fever, as the most frequently recognized symptom of childhood malaria is consistent with some other studies. ${ }^{13}$. The low perception of danger of convulsion in childhood malaria seen here has been documented in Western Nigeria $^{14}$. This may be because the fever is controlled before it gets to the stage of convulsion.

The high percentage of mothers whose children had suspected malaria in the study was comparable to the finding from a similar study on prevalence of childhood malaria $^{15}$. The delay in seeking treatment is similar in finding in a study in Northern Nigeria. ${ }^{5}$ The delay may be due to the low awareness of the cause of malaria. It may also be due to the fact that whereas majority of the respondents viewed childhood malaria as being a very serious problem, they only perceived it as being serious in later stages when the child fails to recover from the first line of treatment or in complicated cases. Further studies are necessary for this.

In this study, $13.6 \%$ of mothers chose treatment at home first, contrasting with a study in Southeast Nigeria where it was $3.4 \%{ }^{15}$ and that in Northeast Nigeria where it was $60.2 \%{ }^{16}$. Treatment at home was mostly undertaken because of good personal experience. Documented 
Table 2: association between education and correct knowledge of cause of malaria $(n=236)$

\begin{tabular}{lccc}
\hline Level of education & Knowledge of mosquito bites as cause of malaria \\
\hline & YES & NO & 174 \\
No Formal education & 59 & 115 & 62 \\
Formal education & 24 & 38 & 236 \\
TOTAL & 83 & 153 & \\
$2=0.4622$ & $\mathrm{P}=0.4966$ & & \\
\hline \hline
\end{tabular}

\begin{tabular}{|c|c|c|}
\hline Signs \& Symptoms & No. & $\%$ \\
\hline Fever & 170 & 72.0 \\
\hline Shivering / Feels cold & 142 & 60.2 \\
\hline Yellow eyes & 20 & 8.9 \\
\hline Headache & 36 & 15.3 \\
\hline Anaemia & 20 & 8.9 \\
\hline Convulsion & 8 & 3.8 \\
\hline Vomiting & 22 & 9.3 \\
\hline Diarrhoea & 4 & 1.7 \\
\hline Loss of appetite & 83 & 35.2 \\
\hline
\end{tabular}

\begin{tabular}{lcc|}
\hline \multicolumn{2}{|c|}{$\begin{array}{c}\text { Table 4: } \\
\text { was first sought for malaria in children } \\
(\mathbf{n = 1 7 6 )}\end{array}$} \\
\hline \multicolumn{1}{|c}{ Choice } & No. & $\%$ \\
\hline Health Centre & 37 & 21.0 \\
Government Hospital & 28 & 15.9 \\
Private Hospital & 18 & 10.2 \\
Treatment at home & 24 & 13.6 \\
Patent medical dealers & 24 & 13.6 \\
Traditional Healer & 13 & 7.4 \\
Community Health Worker & 26 & 14.8 \\
Neighbour & 3 & 1.7 \\
Lab. & 2 & 1.2 \\
Others & 1 & 0.6 \\
Total & 176 & 100.0 \\
\hline
\end{tabular}

reasons for widespread use of self medication include cost of seeking health care from the formal health services and distance ${ }^{17}$. Unlike in other studies in Nigeria and elsewhere ${ }^{16,}{ }^{18}$ where self medication was the most preferred first option for management of childhood malaria, this was not the case in this study. It is likely that the reported good services in the health facilities, which include efficacy of treatment given and the availability of a doctor, made it of more proven value than self medication. Potential dangers of self medication have been documented ${ }^{19,20,21}$ and so should not be encouraged without proper education.

Patent medicine dealers were not the most commonly chosen option here in contrast with another study in Nigeria. ${ }^{15}$ This may be due to better service from the health facilities outweighing that of the patent dealers in terms of efficacy of drugs vis-à-vis cost and full recovery of the child. Further investigation of this finding is necessary before valid conclusions can be drawn.

Traditional healers were rarely used as first port of call as has been documented before ${ }^{15}$. The major reason for their consultation here was their "inexpensive" services. In another study, they were consulted most frequently for cases of convulsion ${ }^{22}$.

Proximity was the major reason for utilizing the services of the community health workers. The advantages of training and maximizing their use are obvious. They are close to the people, can give early diagnosis and treatment and can refer a very ill person to the hospital

The availability of doctor/trained personnel, given as the major reason for the choice of the health centre as initial care provider, corresponds with similar studies. ${ }^{15}$ The need to have readily available trained health staff in the health centres resident in the community cannot be overemphasized. Distance was not a major factor here because the health centre was near enough. Although the government hospital was about 22 kilometres away, the good service they perceived they were getting there outweighed any considerations of distance for those who used it as their initial source of treatment.

The fact that lack of money was the commonest reason for not seeking treatment first in a health facility, underlines the role poverty and competing needs play in hindering access to treatment in the health facilities. The average cost of a single treatment for uncomplicated childhood malaria in the health centre is about N300.00 ( 2.1USD). The cost of orthodox health care as a hindrance to access has been documented in a similar study ${ }^{15}$. The choice of treatment has also been shown to be dependent on access, attitude towards provider and beliefs about the disease ${ }^{23}$ Distance and cost as main constraints to proper utilization of the health centre for malaria have been highlighted in other studies. ${ }^{22,24}$

The low level of awareness of the mothers of the cause of malaria may increase the morbidity and mortality of malaria in children and needs to be rectified by health education intervention programmes which will address wrong beliefs and perceptions. This is in line with building community awareness as part of the elements of the Roll Back Malaria Initiative $^{25}$.

The treatment-seeking behaviour of each community is largely determined by their perception of the relative 


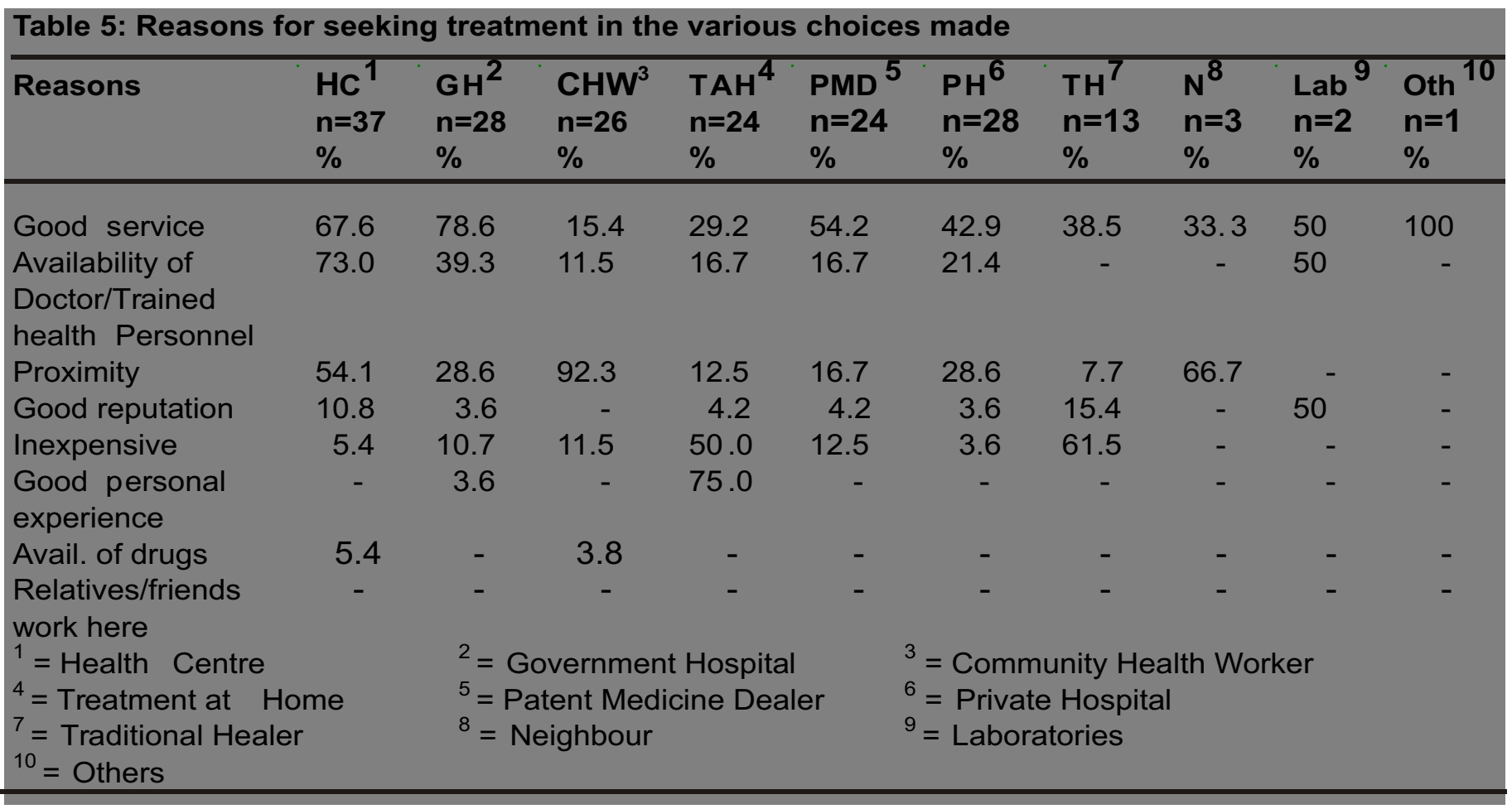

$\begin{array}{lcc}\text { Table 6: } \begin{array}{c}\text { M ain reasons why treatment was not sought in } \\ \text { the health facil }\end{array} & \begin{array}{c}\text { ities (public and private)/chw } \\ \text { Reasons }\end{array} & \begin{array}{c}\text { Frequency } \\ \text { (n=67) }\end{array} \\ \text { Not severe enough } & 6 & 3.9 \\ \text { Did not trust treatment } & 2 & 3.0 \\ \text { Not enough money } & 43 & 64.2 \\ \text { Too far away } & 8 & 11.9 \\ \text { Could not get transport } & 6 & 9.0 \\ \text { Family would not let me } & 1 & 1.5 \\ \text { Religious reasons } & 1 & 1.5 \\ \text { Total } & 67 & 100.0\end{array}$

Usefulness of competing care systems ${ }^{26}$. The poor treatment-seeking behaviour shown in this study by the lower level of use of the health facilities as a place where treatment is first sought (totalling $47.1 \%$ ), and the delay in seeking treatment for childhood malaria, suggest a need for health education suggest a need for health education intervention programmes and putting in place measures to relieve poverty and reduce cost of allopathic care.

Given the higher percentage use of alternative health care providers and home treatment as a place where treatment is first sought (totalling $52.9 \%$ ), it is recommended that this category be trained to diagnose, treat malaria correctly in children and recognise when to refer to the health facilities. This will aid rapid diagnosis and treatment of malaria, an essential element of the Roll Back Malaria Initiative ${ }^{25}$.

\section{References}

1. Federal Ministry of Health, Abuja Nigeria. Malaria control in Africa in the new millennium. African Summit on Roll Back Malaria, Abuja 2000 Working Document

2. WHO. Severe Falciparum malaria. Transactions of the Royal Society of Tropical Medicine \& Hygiene 2000; 94. Supplement 1
3. Federal Ministry of Health. The National Health Policy of Nigeria. FMOH, Lagos, Nigeria. 1992

4. Salako L.A, Brieger W.R, Afolabi B.M et al. Treatment of childhood fevers and illnesses in three rural Nigerian communities. J. Trop Paediatrics 2001; 47: 230238

5. Feyisetan B.J, Asa S and Ebigbola J.A. Mothers' management of childhood diseases in Yoruba land: The influence of cultural beliefs. Health Transit Rev. 1997; 7: 221-234

6. Tanner M and Vlassoff C. Treatment-seeking behaviour for malaria: a typology based on endemicity and gender. Social Science and Medicine 1998; 46(4-5): 523532

7. Araoye M.O. Research methodology with statistics for health and social sciences. Nathadex Publishers 2003; 119-120

8. Des-Fontaines M. Evaluation of practice and cost of vector control on a family level in Central Africa and Douala city, Cameroon. Annals of the society of Belgian tropical Medicine 1991; 71(4): 259-266 
9. Tumwesigire Sam and Watson Sharon. Healthseeking behaviour by families of children suspected to have malaria in Kabale, Uganda. African Health Sciences 2002; 2(3): 94-98

10. Mutero C.M, Ouma J H, Agak B.K, Wanderi J.A and Copeland R.S. Malaria prevalence and use of selfprotection measures against mosquitoes in Suba district, Kenya. East African Medical Journal 1998; 75(1)

11. Munguti K.J. Community perceptions and treatment-seeking for malaria in Baringo district, Kenya: Implications for disease control. East African Medical Journal 1998; 75: 687-691

12. Onwujekwe O.E, Akahara C, Uzochukwu B.S.C and Shu E N. Should we really be promoting home or community based malaria treatment? Insight from a study in south-east Nigeria on the treatment of childhood malaria. Journal of College of Medicine 2003; 8(1): 20-22

13. Miguel C.A, Manderson L and Lansang MaryAnn. Patterns of Reaction for Malaria in Tayabas, the Philippines: Implications for Control. Tropical Medicine and International Health 1998; 3(5): 413-421

14. Ramakrishna J, Brieger W.R and Adeniyi J.D. Reactions of Malaria and Febrile Convulsions: An educational Diagnosis of Yoruba beliefs. International Quarterly of Community Health Education 1989-1990; 9(4)

15. Uzochukwu B.S.C. and Onwujekwe O.E. Socioeconomic differences and health-seeking behaviour for the diagnosis and treatment of malaria: a case study of four local government areas operating the Bamako initiative programme in south-east Nigeria. International Journal for Equity in health 2004, 3:6

16. Akogun O.B and John K.K. Illness related practices for the management of childhood malaria among the Bwatiye people of north-eastern Nigeria. Malaria Journal 2005; 4: 13
17. Foster S. Treatment of malaria outside the formal health services. J Trop Medical \& Hygiene 1995; 98: 29-34

18. Muller O, Traore $\mathrm{C}$, Becher $\mathrm{H}$ and Kouyate $\mathrm{B}$. Malaria morbidity, treatment-seeking behaviour and mortality in a cohort of young children in rural Burkina Faso. Tropical Medicine and international Health 2003;8(4): 290-6

19. Deressa W, Ali A and Engusellassie F. Self treatment of malaria in rural communities, Butajira, Southern Ethiopia. Bulletin of the World Health 2003; 81: 261-268

20. McCombie S.C. Self treatment for malaria: the evidence and methodological issues. Health Policy and Planning 2002; 17: 333-344

21. Gomes $M$, Wayling S and Pang L. Interventions to improve the use of antimalarials in South Asia: an overview. Bulletin of the World Health Organisation 1998; 76(suppl. 1): 9-20

22. Mboera L.E.G, Kamugisha M.L, Barongo $\mathrm{V}$ et al. Community knowledge, perceptions and practices on malaria in mpwapwa district, Central Tanzania. Tanzania Health Research Bulletin 2004; 6(2): 37-41

23. McCombie S.C. Treatment-seeking for malaria: a review of research report. Social Science and Medicine 1996; 43(6): 933-945

24. Amuge B, Wabwire-Mangen F, Puta $\mathrm{C}$ et al. Health-seeking behaviour for malaria among child and adult headed households in Rakai district, Uganda. African Health Sciences 2004; 4(2): 119-124

25. Roll Back Malaria/World Health Organisation. Roll Back Malaria, Promise of progress. 2000

26. Salako LA. An African perspective. World health. $51^{\text {st }}$ year, May-June 1998; 3: 24. 